Rubric 2. SCIENTIFIC AND PRACTICAL DEVELOPMENTS

Field - Electrical Engineering

DOI10.17816/transsyst20206343-59

\author{
(C) H. Almujibah ${ }^{1,2}$, S. I. Kaduk ${ }^{1}$, J. Preston ${ }^{1}$ \\ ${ }^{1}$ University of Southampton \\ (Southampton, United Kingdom) \\ ${ }^{2}$ Taif University \\ (Taif, Saudi Arabia)
}

\title{
HYPERLOOP - PREDICTION OF SOCIAL AND PHYSIOLOGICAL COSTS
}

Background: Hyperloop is a new technological concept for a very fast magnetic levitation train that would travel through soft vacuum tubes and could achieve a speed of up to $1,200 \mathrm{~km} / \mathrm{h}$. As a new transportation system, it might bring some challenges related to human factors that should be tested and considered when designing and propagating Hyperloop.

Aim: This paper used literature review to identify potential physiological and social challenges. Some of these challenges might be high speed, high acceleration /deceleration, large magnetic forces, safety concerns, air pressure, motion sickness and cost as potential human-related challenges.

Methods: In this case, the method of literature review aimed to evaluate the potential physiological effect of these factors on the passengers. It investigated physiological consequences of very high speed, high acceleration/deceleration, and a high magnetic field, as well as human factors of the Maglev trains.

Results: The literature identified high acceleration/deceleration, high speed and high magnetic field as potential risks or sources of discomfort for the passengers.

Conclusion: To the knowledge of the authors, it is the first attempt to identify social and physiological challenges related to the Hyperloop trains concept. It is aimed to inform the development and policies to achieve the safest and most comfortable transportation form.

Key words: Hyperloop, very fast trains, magnetic levitation trains, human factors, physiology, social cost, acceleration, deceleration, magnetic field, motion sickness, very high speed, $g$ force

\section{INTRODUCTION OF HYPERLOOP}

In the middle of 2013, Elon Musk published the concept of Hyperloop for high-speed transportation in his white Alpha paper for a proposed line between San Francisco and Los Angeles, as capsules running into a tube with air evacuated at high speeds. Therefore, this new transport technology accounting as the fifth transport mode to be a faster alternative to uneconomical and not ecologically sustainable traditional modes such as aeroplanes and railways, where magnetically levitated capsules are propelled at speeds up to $1,200 \mathrm{~km} / \mathrm{h}$ [1]. In this case, the lane-switching technology was studied by the Hyperloop 
Hardt in Delft, which allow capsules to change from one lane to another without additional or moving parts. This will allow the pods to reach their high speeds, merge in and out of the network, and smoothly switch routes. In order to switch lanes and allow pods to travel at full speeds in the main tube, the capsules and the track interact with one another [1]. Since the introduction of the Hyperloop concept, the number of developers, academia, and industries across the world has started to investigate related challenges and technical requirements. Thereupon, several organizations have started developing some form of Hyperloop, such as Virgin Hyperloop One and Hyperloop Transportation Technologies (USA), TransPod (Canada), DGW Hyperloop (India), etc. [1]. Many feasibility studies were conducted for the introduction of Hyperloop, among others in France, USA, Russia, Saudi Arabia, the UK, India, USA, China, and Sweden. For example, Virgin Hyperloop One in 2017 has built a test track facility known as DevLoop in Clark County, Nevada with a diameter of $3.3 \mathrm{~m}$ and a length of $500 \mathrm{~m}$ for a historic test speed record of about $387 \mathrm{~km} / \mathrm{h}$. Moreover, the Hyperloop Transportation Technologies (HTT) is working on a full scale of testing facilities in Toulouse, France known as Aerospace Valley with a diameter of $4 \mathrm{~m}$ and a length of $1 \mathrm{~km}$ tube that will accommodate a fullsize vehicle [1]. As a new form of transport, Hyperloop might introduce some new benefits and challenges that need to be investigated and modelled. Hyperloop represents a very high investment. Therefore, it should be confronted with other investments to improve life quality and not just with other transportation systems. For instance, the investment to improve the communication network could not bring better life quality and replace the necessity to connect cities. In this case, the Hyperloop could be accelerating, particularly in the environment of Corona Virus worldwide, as people may will prefer lower density network and more point to point like a Hyperloop instead of cramming into high-density fixed infrastructure such as trains and airports. However, the Corona Virus leads the governments to put more efforts in developing Hyperloop, as it might be the best suitable transport mode especially regarding the environment. This paper investigated the potential social and physiological costs of Hyperloop, which is related to physiology and based on the literature review. The aim of these investigations is to predict and reduce potential risks through the literature review of Hyperloop technology.

\section{HYPERLOOP AND INFRASTRUCTURE ENGINEERING}

The Hyperloop system would be the best transport mode to connect the major cities to integrate commercial and labour markets, as well as to fully utilize the capacity of national airports. In terms of infrastructure engineering, the Hyperloop contains several individual components such as capsule, tube, pillars/ or tunnels, stations, and propulsion. 


\subsection{Pods or capsules}

The development of the capsule aims to maximize its' capacity. On one hand, the sealed capsule would have a low capacity of 28-40 passengers, and it would be supported by air bearing, using an aerodynamic lift and compressed air reservoir [2]. In Musk's proposal, the suggested average capacity was 840 passengers per hour departing every 2 minutes, with the potential to increase up to 3,360 passengers by increasing the frequency of the pods' departures to every 30 seconds. On the other hand, a capacity of 3,600 passengers per hour was suggested by HTT, mainly based on pods with a capacity of 40 passengers and departing every 40 seconds [3].

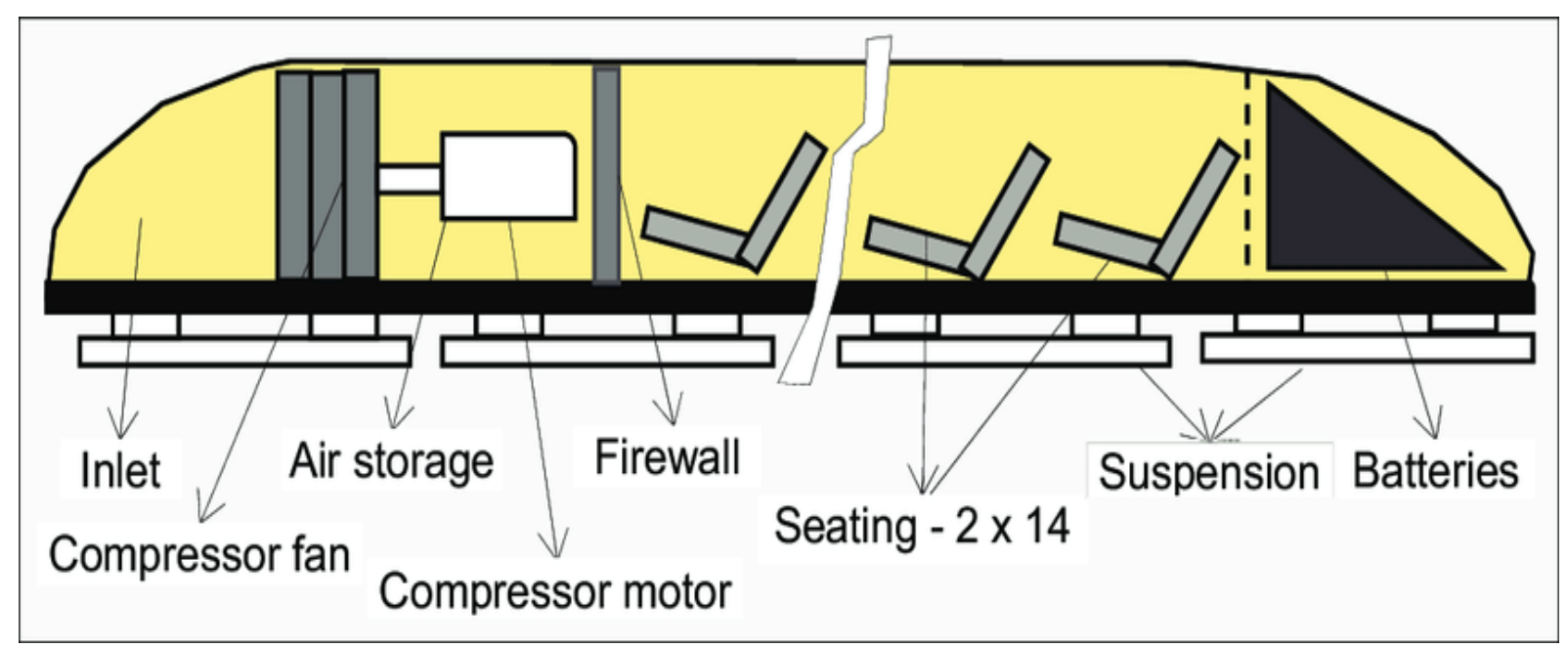

Fig. 1. Hyperloop passenger capsule [4]

In Fig. 1, the capsules consist of eight parts, including inlet, compressor fan, air storage, compressor motor, firewall, seating compartment, suspension, and batteries. The inlets are placed on the low-pressure tube without chocking the air by using the compressor, while the regenerative braking system for the braking purpose of the capsule would be used when the compressor motor acts as a generator and would recharge the battery $[5,6]$.

As a part of the Hyperloop capsule, the firewall or sound bulkhead would divide the passengers' seating couch from the compressor motor. In terms of the suspension component, there would be a substantial technical challenge of suspending the capsule through the tube, which would be related to the velocities of the transonic cruising. To use the ambient atmosphere in the tube, the air bearings suspension would provide the extremely low drug and stability at a possible cost. Regarding the safety and reliability of the capsule, the stiff air bearing suspension as shown in Fig. 2 would be satisfactory; however, it could create considerable discomfort on board for passengers [7]. 


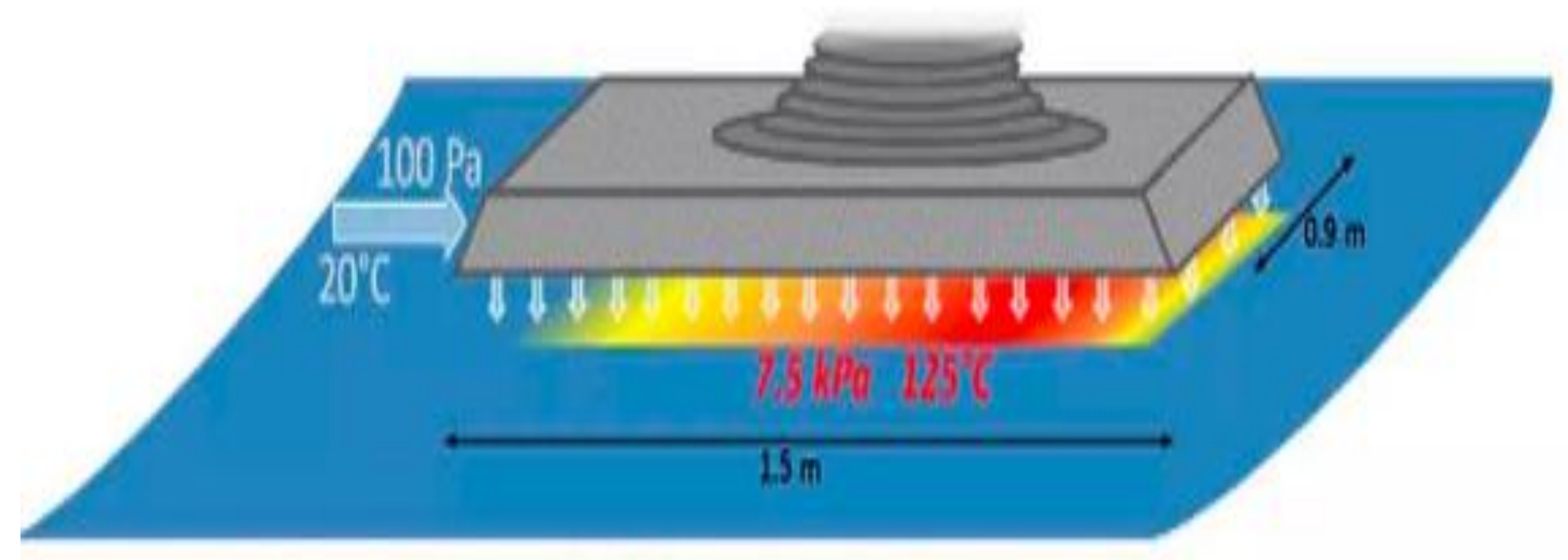

Fig. 2. The suspension system of Hyperloop [7]

In terms of the batteries, the passenger capsule would have an estimated battery of $1,500 \mathrm{~kg}$ that could provide 45 minutes of on-board power of a compressor, as the on-board batteries would be charged at the stations and changed at each stop. Additionally, the batteries would be able to store enough energy to power the fan during the journey and operate the system at night and during the extended cloudy weather [2].

As a result of the interior of the Hyperloop capsule, it is designed with comfort and safety, as the seats adapt to maintain the comfort of the body during the high-speed acceleration that would be experienced during the travel. Additionally, passengers would be able to access their system of personal entertainment, as well as the cabin, would have an aesthetically pleasing display [7].

\subsection{Tube}

The Hyperloop tube is considered as one of the main components of the Hyperloop transport system. It would be made of steel, as there are two parallel tubes welded together side by side to allow capsules to travel in both directions. They would be covered by solar arrays to provide power to the system as shown in Fig. 3. In some sections of the tube, the static portion of the linear motors would be mounted to provide the acceleration and braking, as well as help in guiding the banking of the capsule around the curves [2].

In terms of geometry, the inner diameter of the passenger-only Hyperloop version tube is estimated to be around $2.23 \mathrm{~m}$, with a cross-sectional area of $3.91 \mathrm{~m}^{2}$. Additionally, the inner diameter of the tube would be small enough to reduce the material cost, and the choice of material would be the uniform thickness steel reinforced with stringers. The solar panels that would be placed on the top of the tubes would provide the required system energy, which represents a rough area of $4.25 \mathrm{~m}$ wide for more than $563 \mathrm{~km}$ of the length of the tube. In this case, the expected production of solar panel energy would be $120 \mathrm{~W} / \mathrm{m}^{2}$ and could produce up to $285 \mathrm{MW}$ at peak solar activity [2]. 


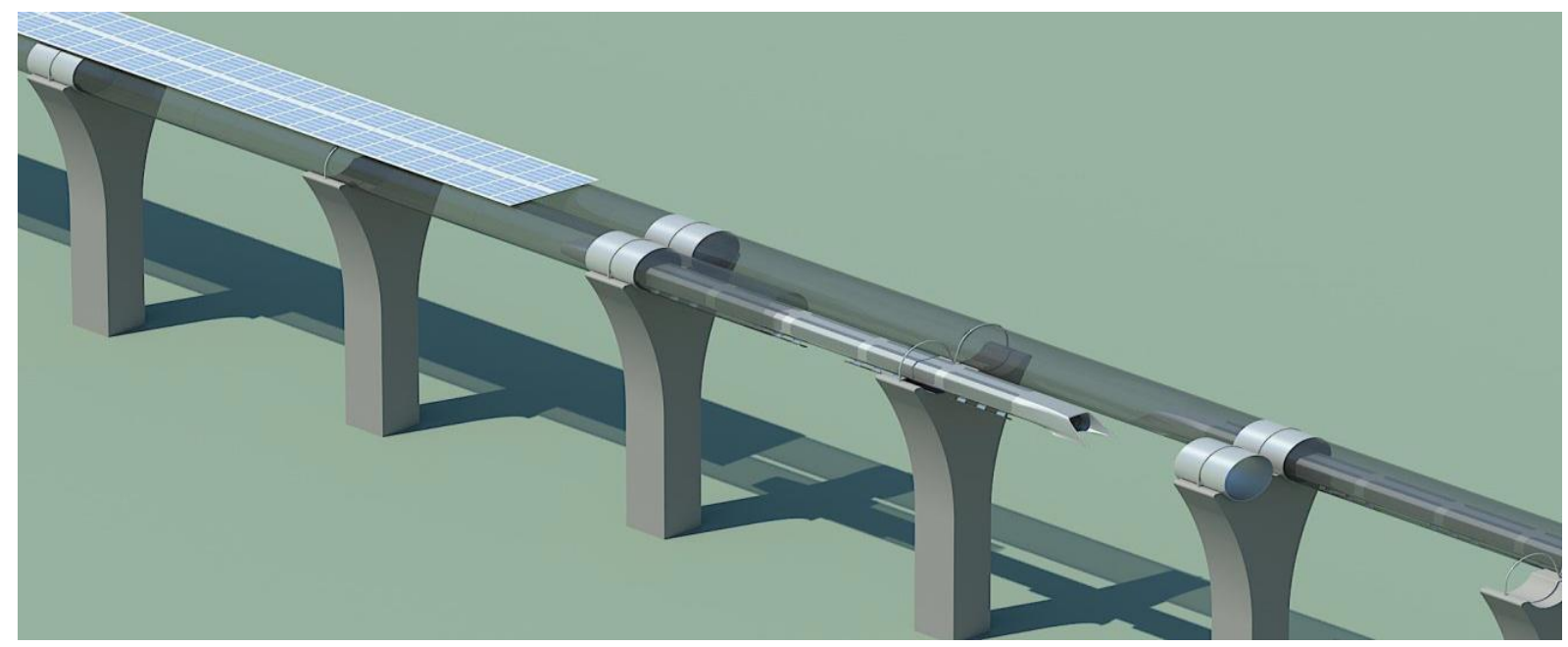

Fig. 3. Hyperloop welded tube [2]

\subsection{Pillars}

The Hyperloop tube would be supported by pillars within the average spacing of roughly every $30 \mathrm{~m}$, as the pillar would be $6 \mathrm{~m}$ tall. In such a case, the short distance between pillars would keep the capsule steadier and the journey more enjoyable by reducing the deflection of the tube [2]. The pillars would be also adjustable connecting to the tube vertically and laterally as shown in Fig. 4 to ensure proper alignment despite possible ground settling. Additionally, there would be dampers incorporated between the tubes and pillars to isolate movements in the ground caused by the tube [2].

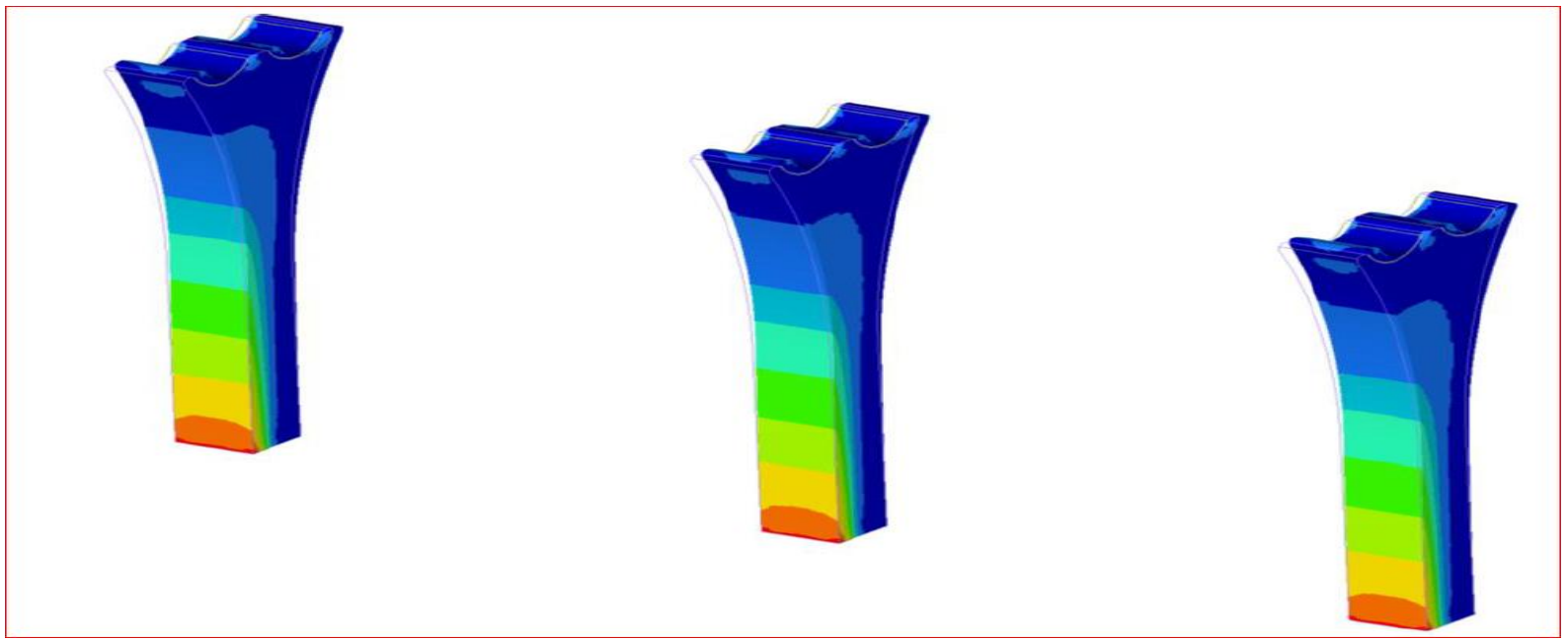

Fig. 4. The pillars of the Hyperloop system [2]

The reinforced concrete would be carefully selected for the construction of pillars due to the sheer quantity of pillars required and its' very low cost per volume [2]. 


\subsection{Stations}

The construction of the Hyperloop station would be different in design from the normal train stations due to the vacuum and requirements of structure related to the pressure hall. The flow of passengers would be evenly distributed, which would lead to less horizontal and vertical circulation to and from the platform as shown in Fig. 5.

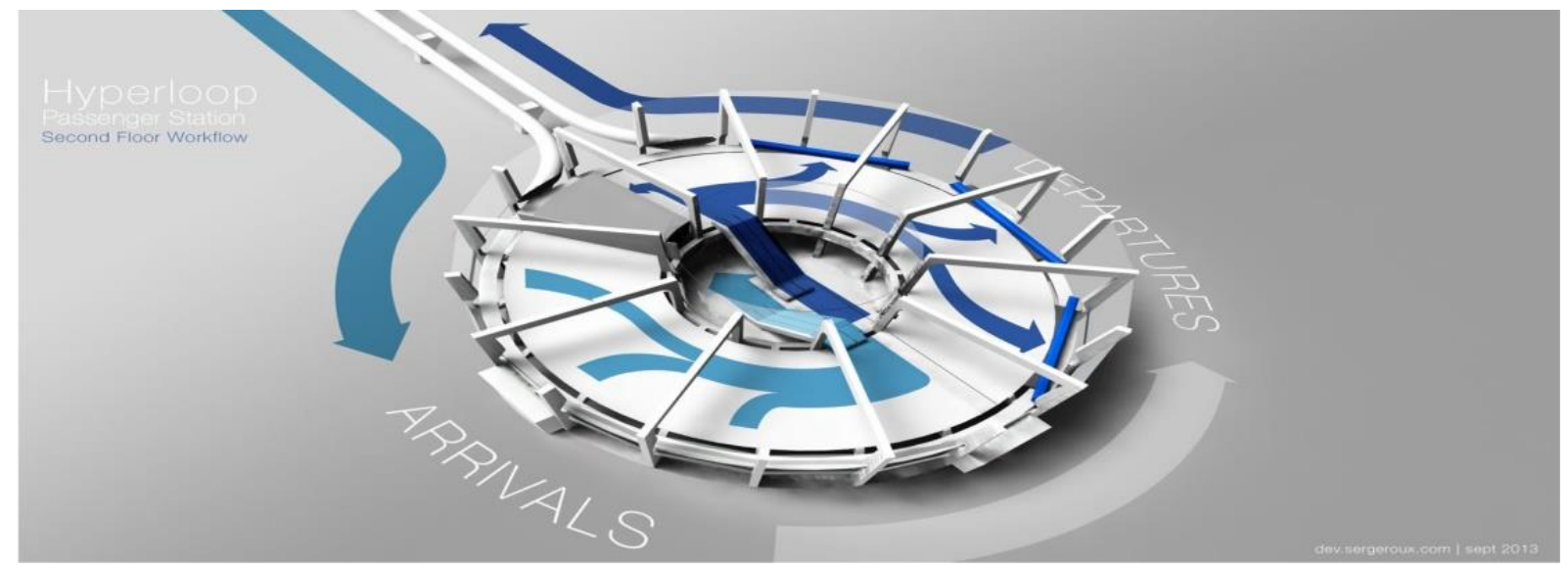

Fig. 5. The proposed Hyperloop station [8]

However, the flow of the passengers would be affected by three main factors on the station: the layout and location of facilities on the station, the number of people passing through the station and their characteristics, and finally how people would find their way on the station [9]. Due to the presence of several carriages where passengers could enter/or exit, the capsules will have efficient boarding times, as the processes of boarding, security screening, and baggage handling is expected to be similar to the airports and special handling by staff might be required. In this case, it is anticipated to be smoothly running due to the regular departure of capsules which will result in steady and fast flow of passengers. Nevertheless, there could be a pressure where more passengers arrive than the number of capsules that are available, resulting in increasing in boarding times by forming queues. For the Hyperloop transport system, two main types of stations are planned. First, the regular station that would be in essence a stop for the main transportation type, as passengers could only get in this transport mode to get to their destination. Second, the transfer station, which would also be called the transportation hub and it would combine several types of transportation modes, as the passengers could come to pick their type of transport from the outside of the station, or the other transportation modes [9].

\section{INTRODUCTION OF THE ASSOCIATION BETWEEN PHYSIOLOGY, HUMAN FACTORS AND TECHNOLOGY}

New transportation forms might affect people in many ways. It is important to model and predict their potential influences to design user-friendly, 
safe and ergonomic transportation systems. Hyperloop will differ from current transportation systems in many ways that might affect the physiology and the perception of the passengers. The speed of the Hyperloop trains will exceed the fastest existing vehicles [10-12]. Due to the high speed, acceleration and deceleration might also be higher. The magnetic field used for the levitation is also a topic worth analysis. Because of that, the literature review was conducted to establish the potential physiological consequences of the Hyperloop trains. This paper attempted to predict how the Hyperloop could affect people physiologically and socially. It used a literature review for the physiological part to investigate how people currently feel about the impact that Hyperloop could have on them. Physiological and social impact are not separate from each other. For example, effects that acceleration might have on the human body could also cause some emotional state in potential users of the technology. At the same time, people could be afraid of some physiological effects of technology, which are not scientifically confirmed. This is a common misunderstanding with the microwave cookers. It is, therefore, important to understand both, how people feel about the technology and what actual predicted effects on the human body are. If the common perception of the technological risks is accurate, then the solution could be a reduction of the risks through the engineering design. Nevertheless, if the fear related to the technology is not founded in the data but misconceptions, then the proper solution should involve social campaigns and spreading the knowledge. The simplified outline of the human-technology interaction belongs to the cultural background of a society. To the knowledge of the authors, it is a first publication that tries to answer a question about necessary human factors considerations in the Hyperloop design.

Technology might affect lifestyle and physiology of people; this might also result in the change of concepts and opinions. Concepts and opinions influence the shape of technology. Similarly, concepts and opinions influence the way and frequency people use technology, while technology might change concepts and opinions.

\section{METHODOLOGY}

\subsection{Methods of the Literature Review}

The main strategy of this literature review was based on the grounded theory approach, that has previously been used in the human factors engineering research [14], as well as the other human factors areas [15]. Grounded theory is used in exploratory social research when the hypotheses are developed in the process of the literature search. The literature is constantly compared to establish search directions. The process is based on induction, deduction, and verification when a researcher is looking for the questions and patterns emerging from the literature. The method uses a strategy of open, axial and selective coding to 
identify main themes or factors for a given problem [16]. Such a strategy was beneficial in case of this paper because of the novelty of this topic.

Hyperloop might introduce some unique factors for transportation, very high speed, possible rapid acceleration/deceleration and magnetic field within the train. This literature review aimed to evaluate the potential physiological effect of these factors on the passengers. To achieve those four searches were conducted using three databases Pubmed, Web of Science and Scopus.

Very high-speed search used the following keywords for the first iteration of search, high speed AND (vehicle OR air* OR space*) AND physiology AND human factors. Further positions were identified based on key references from the selected publications. The result of the search is presented in Table 1. The papers that were duplicated in databases are only listed in one of them.

Table 1. Number of results in physiology and human factors of very high speed

\begin{tabular}{|c|c|c|}
\hline & $\begin{array}{c}\text { Number of initial } \\
\text { results }\end{array}$ & $\begin{array}{c}\text { Number of papers selected for further } \\
\text { evaluation }\end{array}$ \\
\hline Pubmed & 44 & 0 \\
\hline Web of Science & 3 & 0 \\
\hline Scopus & 16802 & 3 \\
\hline Secondary search & & 1 \\
\hline
\end{tabular}

Rapid acceleration search used the following keywords for the first iteration of search, (accelerate* OR decelerate* OR g force) AND (vehicle OR air* OR space*) AND physiology AND human factors. Further positions were identified based on key references from the selected publications. The result of the search is presented in Table 2. The papers that were duplicated in databases are only listed in one of them.

Table 2. Number of results in physiology and human factors of rapid acceleration/deceleration

\begin{tabular}{|c|c|c|}
\hline & $\begin{array}{c}\text { Number of initial } \\
\text { results }\end{array}$ & $\begin{array}{c}\text { Number of papers selected for further } \\
\text { evaluation }\end{array}$ \\
\hline PubMed & 583 & 5 \\
\hline Web of Science & 92 & 3 \\
\hline Scopus & 51308 & 2 \\
\hline Secondary search & & 9 \\
\hline
\end{tabular}

Magnetic field search used the following keywords for the first iteration of search, magnetic field AND (vehicle OR air* OR space*) AND physiology AND human factors. Further positions were identified based on key references from the selected publications. The result of the search is presented in Table 3 . The papers that were duplicated in databases are only listed in one of them. 
Table 3. Number of results in physiology and human factors of the magnetic field

\begin{tabular}{|c|c|c|}
\hline & $\begin{array}{c}\text { Number of initial } \\
\text { results }\end{array}$ & $\begin{array}{c}\text { Number of papers selected for } \\
\text { further evaluation }\end{array}$ \\
\hline PubMed & 81 & 0 \\
\hline Web of Science & 8 & 0 \\
\hline Scopus & 17078 & 7 \\
\hline Secondary search & & 3 \\
\hline
\end{tabular}

Human factors in Maglev search used the following keywords for the first iteration of search, Maglev or Hyperloop AND human factors. Further positions were identified based on key references from the selected publications. The result of the search is presented in Table 4. The papers that were duplicated in databases are only listed in one of them.

Table 4. Number of results in physiology and human factors of Maglev trains

\begin{tabular}{|c|c|c|}
\hline & $\begin{array}{c}\text { Number of initial } \\
\text { results }\end{array}$ & $\begin{array}{c}\text { Number of papers selected for } \\
\text { further evaluation }\end{array}$ \\
\hline PubMed & 1 & 0 \\
\hline Web of Science & 6 & 1 \\
\hline Scopus & 226 & 1 \\
\hline Secondary search & & 1 \\
\hline
\end{tabular}

Inclusion Criteria. Papers included in the further evaluation were peerreviewed publications in English. They had to analyse the physiological effects of very high speed, acceleration, deceleration, magnetic field or the general topic of human factors in Maglev trains. Only publications related to human physiology were included in the evaluation. Only the first 300 results of the search were analysed based on their abstracts. Only publications with full text available were taken into account.

Exclusion Criteria. Experiments conducted on animals, deceased people and human tissues were excluded from the evaluation. Also, studies conducted on unhealthy participants were excluded, as well as studies based only on mathematical models without experimental confirmation of the predictions.

As a result, thirty-six papers were selected for further evaluation, four in the area of very high speed, nineteen in the area of acceleration/deceleration, ten in the area of the magnetic field, and three in the area of human factors in Maglev trains. These papers will be described in detail in the results chapter.

\section{RESULTS AND DISCUSSION}

\subsection{Results of the Literature Review}

\subsubsection{Very High Speed}

The maximum speed of the Hyperloop system is predicted to be $1,200 \mathrm{~km} / \mathrm{h}$. In order to reach the maximum speed, one of the biggest challenges 
of the Hyperloop will technically be how to reduce the pressure between the tube and capsule, which will results in two main benefits; one, removing the air resistance, and two, propelling the trains at maximum speeds nearing that of sounds by using the pressure gradient. In the Alpha documents written by Elon Musk, the Hyperloop system will remain at a pressure of around 100 Pascals, as the pressure exerted on the inside of the tube will remain at about 0.015 Pascals, whereas the atmospheric pressure on the outside of the tube is around 15 Pascals. [17]. In this case, the operating principle of Hyperloop is a transport container (pod) that moves in near-vacuum in a tube as shown in Fig. 6.

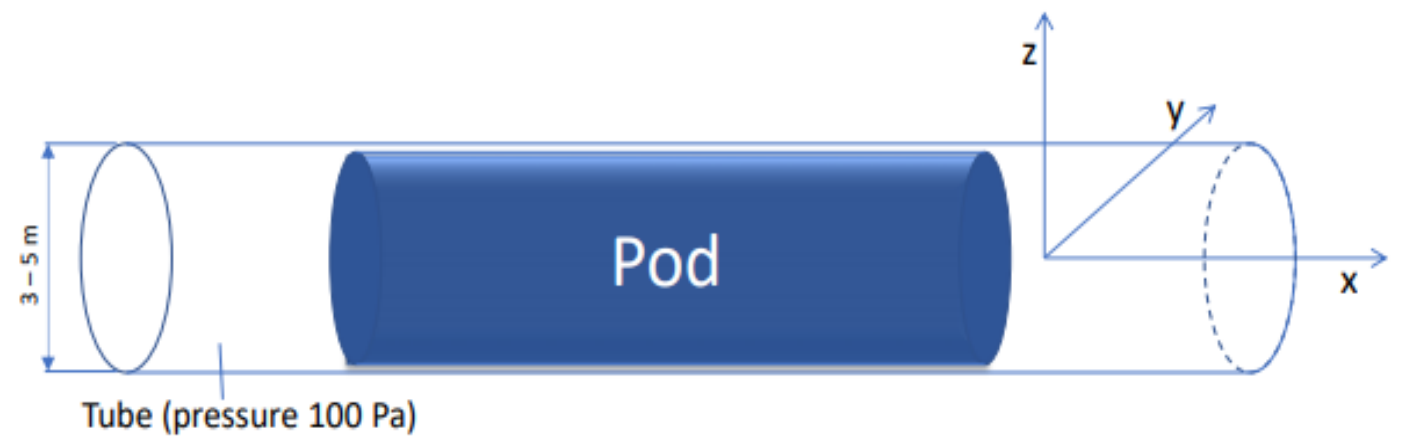

Fig. 6. The pressure of Hyperloop tube [17]

Evaluated research papers analysed speed much slower than the potential speed of Hyperloop. Therefore, they can only be treated as a prediction of the consequences of such a high speed. The study of the car passengers has shown that participants experienced tension and increased activity of the sympathetic nervous system when the speed of the car was increased to $120 \mathrm{~km} / \mathrm{h}$. Some of the measures presented a gradual increase of tension and sympathetic nervous system activity with every increase of speed $(0 \mathrm{~km} / \mathrm{h}, 30 \mathrm{~km} / \mathrm{h}, 90 \mathrm{~km} / \mathrm{h}$ and $120 \mathrm{~km} / \mathrm{h})$, while some only changed with the higher speed levels $(90 \mathrm{~km} / \mathrm{h}$ and $120 \mathrm{~km} / \mathrm{h}$ ) [18]. The military personnel using high-speed boats (40 knots) was repeatedly reported to have decreased cognitive and physical performance just after the transit $[19,20]$; however, it was partially explained by shocks and vibration [21], which could be eliminated in the Hyperloop trains.

\subsubsection{Acceleration/Deceleration}

Acceleration and deceleration change the magnitude of the gravitational power working on the passengers. Because of the high speed, Hyperloop might also use rapid acceleration and rapid deceleration. Such forces can also occur in the case of emergency braking. The estimations of the acceleration in Hyperloop are between $0.5 \mathrm{~g}$ and $5 \mathrm{~g}$, and 0.1 or 0.2 for the deceleration [17]. Many studies have been conducted in the area of the g-force influence on the pilots and drivers, which can be also applicable for $\mathrm{g}$-force in Hyperloop. Increased g-force has been repeatedly proven to have a negative cognitive and physiological effect on people to the extent of temporary loss of consciousness (G-LOC) observed in 
pilots [22, 23] and racing drivers [24]. It can also have some long-term negative health effects.

Passengers of the cars were shown to experience higher stress and tension with the rapid acceleration and deceleration (18). High g-force requires a passenger to use a lot of energy to stabilize themselves [24]. G-force over $3 \mathrm{~g}$ might lead to breathing problems and restricted vision [24]. Passengers exposed to unexpected acceleration or deceleration often display high neck muscle effort that might lead to whiplash injuries [25, 26]. Many pilots report negative symptoms related to high g-forces, for example, abnormal sensations in limbs, disorientation, or confusion [27]. Studies in the centrifuge have shown that high sustained acceleration can lead to the decreased contrast sensitivity for a period of 5-12 minutes [28], as well as psychological stress [29].

Increasing g-force leads to changes in the blood flow from the heart to the brain that might cause temporary loss of consciousness. Full unconsciousness mostly lasts around twelve seconds and is followed by twelve seconds of confusions. It is also preceded and followed by a period of decreased cognitive and psychomotor functioning [23, 30]. Potential long-term consequences of repetitive exposure that are related to rapid acceleration/deceleration include whiplash injuries [25] and increased mean arterial blood pressure [31]. Many pilots also experience extremely unstable gait, called "the wobblies", which can last even three weeks after exposure to the high g-force [32].

\subsubsection{Magnetic Field}

Maglev trains use magnets that create a magnetic field of $0.9 \mathrm{~T}$ at the level of the train's floor and $0.4 \mathrm{~T}$ at the level of the ceiling when no shielding is used [33]. This level of the magnetic field is over 5,000 times more than the earth's magnetic field [34]. It can be expected that magnetic field in Hyperloop is going to be similar. The human brain reacts to even small changes in the magnetic field in a similar way as other environmental stressors [35]; however, the extent and type of the effect reported varies depending on the experiment. Studies on the influence of the magnetic field on health showed no effect of $0.3 \mathrm{~T}$ on melatonin secretion [36], no effect of $8 \mathrm{~T}$ on body temperature, heart rate, respiration, blood pressure or cognitive functioning [37], and no effect $28 \mathrm{mT}$ on heart rate variability [38]. However, one case study reported a slowing of heart rate in a woman exposed to the extremely low-frequency magnetic field at a workplace that decreased when exposure finished [39]. Also, another study found a slight increase in the systolic blood pressure caused by an increase in the magnetic field [40].

The intermittent, repetitive electromagnetic field of $0.2 \mathrm{mT}$ was observed to change the circadian rhythm of the heart rate delaying the heart rate nadir [41], but the continuous one did not display such an effect [42].

The constant magnetic field of 1.5 Tesla was found to have an adverse effect on hand coordination and near visual contrast sensitivity [43]. There are 
also other subtle neuropsychological changes reported by several studies [44]. However, other studies found no effect on the neuropsychological function of the 0.4 Tesla magnetic field [45] and no difference between $0.5 \mathrm{~T}$ and $8 \mathrm{~T}$ magnetic field [40,46]. Even with the absence of measurable neuropsychological changes, some people report dizziness, metallic taste in the mouth, or discomfort when they enter a high magnetic field [40]. Some people report increased sensitivity to the magnetic fields and some adverse health effects related to the magnetic fields; however, scientific experiments did not manage to confirm the connection between magnetic fields and reported syndromes $[47,48]$.

\subsubsection{Human Factors in Maglev and other high-speed trains}

Hyperloop is still a technology in development; therefore, the conclusions about the human factors involved are at the stage of speculation. Studies about human factors in Maglev and other high-speed trains might bring some points to the discussion about the future of Hyperloop. The main human factor studied was the effect of noise. The noise caused by high-speed trains can cause discomfort in passengers and passers-by [49]. It also decreased the cognitive performance of the passengers and their overall satisfaction from the journey [50]. The noise might be absent in Hyperloop, because of the soft vacuum tubes containing the train; and therefore, noise-related discomfort might be highly reduced. However, some studies found that enhanced noise of the train might reduce discomfort caused by other factors, like mobile phones or other passengers. Moreover, discomfort related to the pressure change when the train is passing a tunnel decreases when the train produced higher noise at that time [51].

\subsubsection{Physiological considerations for Hyperloop trains}

Review of the literature showed that $g$-force should be the most important consideration in the Hyperloop design. Both routine acceleration/deceleration should be taken into account as well as g-force in case of emergency braking. Increased g-force can lead to short-term and long-term adverse effects like stress, tension, breathing problems, restricted vision, whiplash, or temporary loss of consciousness. It is not a surprising conclusion as acceleration and deceleration have been one of the most common underlying mechanisms of accident-related injuries [22, 24, 25]. High speed also has the potential to increase tension in passengers, but it could also be an effect of the rapid acceleration [18]. The results regarding the psychophysiological effects of the magnetic field are inconclusive. There is data confirming a negative effect of some frequencies of the magnetic field. At the same time, some studies that examined different frequencies or circumstances report lack of adverse influence. Therefore, it is important to analyse the effect of the magnetic field taking its' particular characteristic into account. As there were some studies reporting adverse effects $[41,43,44]$ it is important to investigate this topic 
more extensively. Hypersensitivity to the magnetic field was not confirmed medically as a condition; however, as some people claim they experience it could influence their decisions on whether to use Hyperloop trains or not. This topic should also be investigated to mitigate the discomfort of the passengers. Many people report discomfort and adverse effects related to the magnetic fields, for example in MRI scanners or the presence of mobile phones. Understanding these phenomena could allow prevention and increase comfort. As so, it is recommended to investigate underlying mechanisms of subjective hypersensitivity to the magnetic field and related discomfort when using devices that generate the magnetic field.

\section{CONCLUSIONS}

Within the introducing of Hyperloop as a new type of on-ground transport technology, it is necessary to study how to avoid harm or financial loss and it is important to predict effects, attitudes and reactions before the technology is released. The human factors considerations could include the door sizes, design of seat, spacing of walkway, seat spacing, design of handle, and systems of security, control and emergency. Additionally, Hyperloop might bring concerns related to the human factors' perspective and could influence the human body, have unknown psychological or cognitive effects, and environmental considerations such as vibration, noise, thermal comfort and lighting.

This paper used a literature review to investigate some social and physiological consequences of Hyperloop technology. They introduced key topics that should be taken into account when designing and propagating Hyperloop trains. There are some issues raised that they perceived as potential future risks or obstacles like air pressure, safety in terrorist attacks or case of the vehicle failure, motion sickness, or acceleration. They stressed the catastrophic consequences of any potential accidents. The Hyperloop is perceived as fast transport, but not comfortable, realistic, safe, sustainable nor affordable. Such opinions could lead to decreased use of this technology, as well as many people could restrain from using it because of the safety issues. Therefore, safety concerns in the case of Hyperloop should be taken very seriously, but also it should be communicated to the potential users that such measures were undertaken. Analysis of the potential physiological risks pointed to high acceleration/deceleration, high speed, and high magnetic fields as potential sources of discomfort or even injuries. Even though electromagnetic sensitivity is not a confirmed medical condition, many people believe they experience it and it might stop them from using Hyperloop trains. Such individuals could be more reluctant to use Hyperloop as a form of transport. As a result, several safety issues were raised both by the specialist literature but also by potential future users of the Hyperloop trains. These issues should be part of the design 
and tests of the Hyperloop but also of the social communication propagating the knowledge about it.

\section{REFERENCES}

1. Transport Systems Catapult. Hyperloop-Opportunity for UK Supply Chain. [Intrnet]. [cited 2020 may 11] Available from: https://s3-eu-west-1.amazonaws.com/media.ts. catapult/wp-content/uploads/2018/10/08153525/00601_Hyperloop-Report.pdf

2. Musk E. Hyperloop alpha. 2013 [Intrnet]. [cited 2020 may 11] Available from: http://www.spacex.com/sites/spacex/files/hyperloop_alpha-20130812.pdf.

3. Walker R. Hyperloop:Cutting through the Hype. TRL the Future of Transport. [Intrnet]. [cited 2020 may 11] Available from: https://trl.co.uk/sites/default/files/Hyperloop\%20 white\%20paper_0.pdf

4. Janic M. Multicriteria evaluation of the high speed rail, transrapid maglev and hyperloop systems. Transportation Systems and Technology. 2018;4(4):5-31. doi: 10.17816/transsyst2018445-31

5. Dhote A. Hyperloop New Mode of Transportation. International Journal of Innovative Science and Research Technology. 2017;2(8): 2456-2165. doi: 10.38124/volume-52020_issue-3-march

6. Abin E, Varsha P. Intelligent Airlock System for Hyperloop with Landing Wheels. Asian Journal of Applied Science and Technology (AJAST). 2017;1(5):22-24. [Intrnet]. [cited 2020 may 11] Available from: http://ajast.net/data/uploads/08.pdf

7. Sonawane A, Kakaso B, Harishchandra B, et al. Hyperloop Technology the Passenger Transport System. Information, Knowledge and Research in Mechanical Engineering. 2017;04(02). 895-897.Available from: http://www.ejournal.aessangli.in/ASEEJournals /mech138.pdf

8. Lavrinc D. Elon Musk's Hyperloop Needs This Gorgeous Passenger Station. [Intrnet]. [cited 2020 may 11] Available from: https://www.wired.com/2013/09/hyperloopstation/

9. Van Houten R. Passenger Flow in an Underground Hyperloop Station. [Intrnet]. [cited 2020 may 11] Available from: https://www.academia.edu/38403352/Passenger_ flow_in_an_undergroundhyperloop_station_RSvanHouten

10. Gonzalez-Gonzalez E, Nogues S. Railways of the future: Evolution and prospects of high-speed rail, maglev and hyperloop (Part 1). 2017; DYNA INGENIERIA E INDUSTRIA [Intrnet]. Publicaciones DYNA. 2017;92(1):371-373. doi: 10.6036/8269.

11. Gonzalez-Gonzalez E, Nogues S. Railways of the future: Evolution and prospects of high-speed rail, maglev and hyperloop (Part 1). 2017; DYNA INGENIERIA E INDUSTRIA [Intrnet]. Publicaciones DYNA. 2017;92(5):483-485. doi: 10.6036/8323.

12. Kumar A, Khan A. Hyperloop High Speed of Transportation. International Journal of Innovative Research in Science and Engineering. 2017; 3(4). 832-841.Available from: http://data.conferenceworld.in/IIMT2017/P430-439.pdf

13. Baggaley K. Elon Musk's hyperloop dream may come true — and soon. [Intrnet]. [cited 2020 may 11] Available from: https://www.nbcnews.com/mach/science/elonmusk-s-hyperloop-dream-may-come-true-soon-ncna855041

14. Parnell K, Stanton N, Plant K. Exploring the mechanisms of distraction from in-vehicle technology: The development of the PARRC model. Safety Science. 2016;87:25-37. doi: 10.1016/j.ssci.2016.03.014.

15. Rafferty L, Stanton N, Walker G. The famous five factors in teamwork: a case study of fratricide. Ergonomics. 2010;53(10):1187-204. doi: 10.1080/00140139.2010.513450. 
16. Heath H, Cowley S. Developing a grounded theory approach: a comparison of Glaser and Strauss. International journal of nursing studies. 2004;41(2):141-50. doi: 10.1016/s0020-7489(03)00113-5

17. Doppelbauer J. Hyperloop - an Innovation for Global Transportation?. [Intrnet]. [cited 2020 may 11] Available from: https://www.era.europa.eu/sites/default/files/ library/docs/hyperloop_innovation_for_global_transportation_en_1.pdf

18. Min B, Chung S, Park S, et al. Autonomic responses of young passengers contingent to the speed and driving mode of a vehicle. International Journal of Industrial Ergonomics. 2002;29(4):187-98. doi: 10.1016/s0169-8141(01)00059-2

19. Myers S, Dobbins T, King S, et al. Physiological consequences of military high-speed boat transits. European journal of applied physiology. 2011;111(9):2041-9. doi: 10.1007/s00421-010-1765-3

20. Myers S, Dobbins T, King S, et al. Effectiveness of suspension seats in maintaining performance following military high-speed boat transits. Human Factors. 2012;54(2):264-76. doi: 10.1177/0018720811436201

21. Olausson K, Garme K. Prediction and evaluation of working conditions on high-speed craft using suspension seat modelling. Proceedings of the Institution of Mechanical Engineers Part M. Journal of Engineering for the Maritime Environment. 2015;229(3):281-90. doi: 10.1177/1475090213515641

22. Green N, Ford S. G-induced loss of consciousness: retrospective survey results from 2259 military aircrew. Aviation, space, and environmental medicine. 2006;77(6):619-26

23. Tripp L, Warm J, Matthews G, et al. + Gz acceleration loss of consciousness: time course of performance deficits with repeated experience. Human factors. 2006;48(1):109-20. doi: 10.1177/154193120204600127

24. Brown J, Stanton N, Revell K. A review of the physical, psychological and psychophysiological effects of motorsport on drivers and their potential influences on cockpit interface design. International Conference on Applied Human Factors and Ergonomics; 2018: Springer. doi: 10.1007/978-3-319-93885-1_46

25. Blouin J, Descarreaux M, Belanger-Gravel A, et al. Attenuation of human neck muscle activity following repeated imposed trunk-forward linear acceleration. Experimental brain research. 2003;150(4):458-64. doi: 10.1007/s00221-003-1466-9

26. Hynes L, Dickey J. The rate of change of acceleration: Implications to head kinematics during rear-end impacts. Accident Analysis \& Prevention. 2008;40(3):1063-8. doi: 10.1016/j.aap.2007.11.012

27. Rickards C, Newman D. G-induced visual and cognitive disturbances in a survey of 65 operational fighter pilots. Aviation, space, and environmental medicine. 2005;76(5):496-500.

28. Chou $\mathrm{P}, \mathrm{Wen} \mathrm{T}, \mathrm{Wu} \mathrm{Y}$, et al. Contrast sensitivity after+ $\mathrm{Gz}$ acceleration. Aviation, space, and environmental medicine. 2003;74(10):1048-51.

29. Lin P, Wang J, Li S. Subjective stress factors in centrifuge training for military aircrews. Appl Ergon. 2012;43(4):658-63. doi: 10.1016/j.apergo.2011.10.002

30. Tripp L, Warm J, Matthews G, et al. On tracking the course of cerebral oxygen saturation and pilot performance during gravity-induced loss of consciousness. Human factors. 2009;51(6):775-84. doi: 10.1177/0018720809359631

31. Newman D, Callister R. Cardiovascular training effects in fighter pilots induced by occupational high $\mathrm{G}$ exposure. Aviation, space, and environmental medicine. 2008;79(8):774-778. doi: 10.3357/asem.1575.2008 
32. Muller T. G-induced vestibular dysfunction ('the wobblies') among acrobatic pilots: A case report and review. Ear, nose \& throat journal. 2002;81(4):269. doi: $10.1177 / 014556130208100416$

33. Lee H, Kim K, Lee J. Review of maglev train technologies. IEEE transactions on magnetics. 2006;42(7):1917-25. doi: 10.1109/tmag.2006.875842

34. Sears FW, Zemansky MW. University Physics. Physics Today. AIP Publishing. 1955;8(11):26-26. doi: 10.1063/1.3061831

35. Carrubba S, Frilot II C, Chesson Jr A, Marino A. Numerical analysis of recurrence plots to detect effect of environmental-strength magnetic fields on human brain electrical activity. Medical engineering \& physics. 2010;32(8):898-907. doi: 10.1016/j.medengphy.2010.06.006

36. Warman G, Tripp H, Warman V, Arendt J. Acute exposure to circularly polarized 50$\mathrm{Hz}$ magnetic fields of 200-300 $\mu \mathrm{T}$ does not affect the pattern of melatonin secretion in young men. The Journal of Clinical Endocrinology \& Metabolism. 2003;88(12):566873. doi: 10.1210/jc.2003-030220

37. Kangarlu A, Burgess $\mathrm{R}$, Zhu $\mathrm{H}$, et al. Cognitive, cardiac, and physiological safety studies in ultra high field magnetic resonance imaging. Magnetic resonance imaging. 1999;17(10):1407-16. doi: 10.1016/s0730-725x(99)00086-7

38. Sait M, Wood A, Kirsner R. Effects of $50 \mathrm{~Hz}$ magnetic field exposure on human heart rate variability with passive tilting. Physiological measurement. 2005;27(1):73. doi: 10.1088/0967-3334/27/1/007

39. Deoux S, Deoux P, Szabason F. Occupational So-Hz Magnetic Field Exposure and Human Heart Rate: A Case Report. Electro-and Magnetobiology. 1997;16(2):153-9.

40. Chakeres D, De Vocht F. Static magnetic field effects on human subjects related to magnetic resonance imaging systems. Progress in biophysics and molecular biology. 2005;87(2-3):255-65. doi: 10.1016/j.pbiomolbio.2004.08.012

41. Griefahn B, Kunemund C, Blaszkewicz M, et al. Experiments on effects of an intermittent $16.7-\mathrm{Hz}$ magnetic field on salivary melatonin concentrations, rectal temperature, and heart rate in humans. International archives of occupational and environmental health. 2002;75(3):171-8. doi: 10.1007/s00420-001-0292-2

42. Griefahn B, Kunemund C, Blaszkewicz M, et al. Experiments on the effects of a continuous $16.7 \mathrm{~Hz}$ magnetic field on melatonin secretion, core body temperature, and heart rates in humans. Bioelectromagnetics: Journal of the Bioelectromagnetics Society, The Society for Physical Regulation in Biology and Medicine, The European Bioelectromagnetics Association. 2001;22(8):581-8. doi: 10.1002/bem.87

43. De Vocht F, Van-Wendel-de-Joode B, Engels H, Kromhout H. Neurobehavioral effects among subjects exposed to high static and gradient magnetic fields from a 1.5 Tesla magnetic resonance imaging system-a case-crossover pilot study. Magnetic Resonance in Medicine: An Official Journal of the International Society for Magnetic Resonance in Medicine. 2003;50(4):670-4. doi: 10.1002/mrm.10604.

44. Sienkiewicz Z, Jones N, Bottomley A. Neurobehavioural effects of electromagnetic fields. Bioelectromagnetics. 2005;26(S7):S116-S26. doi: 10.1002/bem.20141

45. Delhez M, Legros J, Crasson M. No influence of 20 and $400 \mu \mathrm{T}, 50 \mathrm{~Hz}$ magnetic field exposure on cognitive function in humans. Bioelectromagnetics: Journal of the Bioelectromagnetics Society, The Society for Physical Regulation in Biology and Medicine, The European Bioelectromagnetics Association. 2004;25(8):592-8. doi: 10.1002/bem.20040.

46. Chakeres D, Bornstein R, Kangarlu A. Randomized comparison of cognitive function in humans at 0 and 8 Tesla. Journal of Magnetic Resonance Imaging: An Official Journal 
of the International Society for Magnetic Resonance in Medicine. 2003;18(3):342-5. doi: 10.1002/jmri.10366

47. Mueller C, Krueger H, Schierz C. Project NEMESIS: perception of a $50 \mathrm{~Hz}$ electric and magnetic field at low intensities (laboratory experiment). Bioelectromagnetics: Journal of the Bioelectromagnetics Society. The Society for Physical Regulation in Biology and Medicine. The European Bioelectromagnetics Association. 2002;23(1):26-36.

48. Seitz H, Stinner D, Eikmann T, et al. Electromagnetic hypersensitivity (EHS) and subjective health complaints associated with electromagnetic fields of mobile phone communication - a literature review published between 2000 and 2004. Science of the total environment. 2005;349(1-3):45-55. doi: 10.1016/j.scitotenv.2005.05.009

49. Vos J. Annoyance caused by the sounds of a magnetic levitation train. The Journal of the Acoustical Society of America. 2004;115(4):1597-608. doi: 10.1121/1.1650330

50. Wei W, Bockstael A, De Coensel B, Botteldooren D. Interference of speech and interior noise of Chinese high-speed trains with task performance. Acta Acustica united with Acustica. 2012;98(5):790-9. doi: 10.3813/aaa.918560

51. Sanok S, Mendolia F, Wittkowski M, et al. Passenger comfort on high-speed trains: effect of tunnel noise on the subjective assessment of pressure variations. Ergonomics. 2015;58(6):1022-31. doi: 10.1080/00140139.2014.997805

Information about the authors:

Almujibah Hamad, BEng, MEng, PhD Student;

ORCID: 0000-0002-9130-8849;

E-mail: hra1m15@soton.ac.uk

Sylwia Izabela Kaduk, MSc, PgDip, PhD Student;

ORCID: 0000-0003-0730-2389; Scopus ID: 57209316605;

E-mail: sylwia.i.kaduk@gmail.com

Preston John, BA, PhD, Professor in Rail Transport;

ORCID: 0000-0002-6866-049X; Scopus ID: 16200251000;

E-mail: J.M.Preston@ soton.ac.uk

\section{To cite this article:}

Almujibah H, Kaduk SI, Preston J. Hyperloop - Prediction of Social and Physiological Costs. Transportation Systems and Technology. 2020;6(3):43-59. doi: 10.17816/transsyst2020634359 